\title{
Modeling of Microstructure Evolution during Hot Strip Rolling of Dual Phase Steels
}

\author{
Dongsheng LIU, Fateh FAZELI and Matthias MILITZER
}

The Centre for Metallurgical Process Engineering, The University of British Columbia, 309-6350 Stores Road., Vancouver, BC, V6T 1 Z4 Canada.

(Received on August 6, 2007; accepted on October 10, 2007)

\begin{abstract}
Microstructure models for hot strip rolling of $\mathrm{CMnSi}$ and $\mathrm{CMnMo}$ dual-phase steels have been proposed. The constitutive behaviour of austenite prior to the onset of dynamic recrystallization has been described by the physically based Kocks-Mecking model. The static recrystallization kinetics has been simulated by the Johnson-Mehl-Avrami-Kolmogorov (JMAK) theory. The recrystallized austenite grain size is described using an empirical equation considering the effect of strain, prior austenite grain size and deformation temperature. Ferrite transformation start is modeled with an approach that considers early growth of corner nucleated ferrite. The fraction of ferrite transformed from austenite during continuous and/or stepped cooling is described using the JMAK approach in combination with the additivity rule. The ferrite grain size is quantified as a function of the transformation start temperature. The critical conditions for the onset of bainite and martensite transformations in the remaining austenite have been empirically evaluated as a function of ferrite fraction transformed. The microstructure models for these metallurgical phenomena have been validated with experimental studies in the laboratory emphasizing industrially relevant hot strip rolling conditions and run-out table cooling strategies.
\end{abstract}

KEY WORDS: dual phase steels; hot rolling; microstructure; process modeling.

\section{Introduction}

In the last decade the steel industry has developed advanced high strength steels (AHSS), e.g. dual-phase (DP) and transformation-induced plasticity (TRIP) steels, to meet the seemingly conflicting demands of the automotive industry to build vehicles with reduced weight and improved safety at low cost. An ultra light steel auto body (ULSAB) had been proposed by making extensive use of these novel steels that show for a given strength higher formability as compared to conventional high-strength low alloy (HSLA) steels. ${ }^{1-4)}$ Further, AHSS also provide improved crashworthiness. In particular, dual-phase steels are now commercially produced and substantially used in modern vehicle designs.

Microstructure and mechanical properties of dual-phase steels have been extensively studied. ${ }^{5-15)}$ The improved property profile of DP steels results from a composite microstructure where hard martensite islands are imbedded in a soft ferrite matrix with a martensite fraction of approximately $10 \%$ for automotive applications. There are two principal processing routes to produce DP sheet steels: (i) intercritical annealing of cold-rolled steels in a continuous annealing line or hot dip galvanizing line, (ii) hot rolling. For automotive sheets the intercritical annealing route is of primary interest but there are a number of parts where hotrolled DP steels are required, e.g. for wheel rims and discs, hydro-formed tubes. In the hot-rolled processing route it is critical to design an appropriate run-out table cooling path to create the desired ferrite-martensite microstructure. For example, this can be achieved by a stepped cooling path and coiling below the martensite start temperature. Provided there is sufficient cooling capacity available on the run-out table near room temperature coiling can be employed such that hot-rolled DP steels may be produced with simple $\mathrm{Fe}-\mathrm{C}-\mathrm{Mn}-\mathrm{Si}$ chemistries. ${ }^{16)}$ Alternatively, additional alloying with $\mathrm{Cr}$ and, perhaps, Mo facilitates coiling at more conventional temperatures (i.e. $\left.500-600^{\circ} \mathrm{C}\right) .^{17)}$

The design and optimization of the thermomechanical processes during hot strip rolling of DP steels require the knowledge of the underlying metallurgical phenomena, i.e. hot deformation behaviour, recrystallization and austenite decomposition. Starting with the pioneering work of Sellars et al. ${ }^{18,19)}$ to predict microstructure evolution during multipass hot rolling, mathematical modeling of hot strip rolling has meanwhile attained a rather mature level; a number of such models are available for conventional plain carbon and high-strength low alloy (HSLA) steels. ${ }^{20-32)}$ Model development for AHSS steels is still in its infancy; some initial model concepts have recently been proposed for DP steels ${ }^{33-36)}$ and first generation models have also been proposed for TRIP steels. ${ }^{37,38)}$ The development of microstructure process models for advanced high strength steels is particularly significant since these steels are more sensitive to process conditions than conventional steels. Consequently, the availability of process models with predictive capabilities will be of tremendous help to establish robust processing routes for these new steels.

The present paper describes a comprehensive microstructure model for hot rolling of DP steels. Following established approaches for low carbon steels, individual submodels have been developed for microstructure evolution in 
austenite, i.e. static recrystallization and constitutive behaviour, and austenite decomposition into ferrite based on experimental studies. The overall model has been validated by simulating the entire hot strip rolling process with hot torsion tests.

\section{Materials and Experimental Procedures}

\subsection{Materials}

Two steel chemistries that are suitable for dual-phase steels have been investigated. Table 1 gives the details of the chemical compositions together with the Ae3 temperatures, $T_{\mathrm{Ae} 3}$, that have been obtained from Thermo-Calc using the Fe2000 data base. The L-DP steel has a lean $\mathrm{CMnSi}$ chemistry and is a preferred choice for hot-rolled material but requires near room temperature coiling to produce the desired ferrite-martensite microstructure. The second steel, Mo-DP, is alloyed with Mo and gives an example for richer DP chemistries. As a matter of fact, the Mo-DP steel is a classical example of a DP 600 steel produced by the intercritical annealing route. Both steels had been received as transfer bar material from commercial heats.

\subsection{Experimental Procedures}

The investigation of individual microstructure phenomena, i.e. austenite grain growth, constitutive behaviour, recrystallization and austenite decomposition, was conducted on a Gleeble 3500 thermomechanical simulator as described elsewhere in more detail. ${ }^{38)}$ The evaluation of austenite grain growth was restricted to determine reheat conditions in order to obtain suitable austenite grain sizes for subsequent deformation and transformation tests. Uniaxial compression tests were employed to examine the constitutive behaviour and static recrystallization was investigated with the help of interrupted compression tests (so-called double hit tests). The austenite decomposition kinetics was quantified with dilatometer measurements during continuous cooling transformation (CCT). In addition, selected stepped cooling transformation tests were performed. In particular, these tests emphasized to establish the conditions required to form a ferrite-martensite microstructure. For this purpose, a number of different ferrite fractions were produced by variation of the slow cooling (or isothermal) step at ferrite formation temperatures followed by applying different cooling rates to room temperature to identify the critical cooling rate required such that all remaining austenite transforms to martensite rather than to pearlite or bainite.

A Gleeble HTS 100 hot torsion machine was employed to simulate the entire process of hot strip production. The details of the torsion test procedures are described in a recent publication. ${ }^{38)}$ The simulated run-out table cooling sce-

Table 1. Chemical composition of the steels (weight pct).

\begin{tabular}{lcccccccccc}
\hline Steel & $\mathrm{C}$ & $\mathrm{Mn}$ & $\mathrm{P}$ & $\mathrm{S}$ & $\mathrm{Si}$ & $\mathrm{Al}$ & $\mathrm{N}$ & $\mathrm{Ti}$ & $\mathrm{Mo}$ & $T_{A e 3}\left({ }^{\circ} \mathrm{C}\right)$ \\
\hline L-DP & 0.07 & 1.45 & 0.007 & 0.002 & 0.73 & 0.05 & 0.0057 & 0.01 & - & 860 \\
\hline Mo-DP & 0.06 & 1.86 & 0.015 & 0.004 & 0.077 & 0.043 & 0.007 & 0.011 & 0.155 & 822 \\
\hline
\end{tabular}

narios emphasized room temperature coiling.

The test samples were further examined by metallographic techniques and hardness measurements. The microstructure was analyzed for positions at the centre plane perpendicular to the length direction in the samples for grain growth and CCT. For the torsion test samples, microstructure and hardness were investigated at a position $1 \mathrm{~mm}$ below the surface at the centre of the gauge length. Standard procedures were employed in mounting, grinding and polishing these sections to be examined. ${ }^{38)}$ For austenite grain growth tests, the as-quenched samples were tempered at $550^{\circ} \mathrm{C}$ for $20 \mathrm{~h}$ and then sectioned and polished. Saturated aqueous picric acid was used to reveal the austenite grain boundaries. The etching procedure used for multiphase microstructure characterization was as follow: $3 \mathrm{~s}$ pre-etching in $2 \%$ nital, rinse in water, and final etching for $20 \mathrm{~s}$ in $10 \%$ sodium meta-bisulfite aqueous solution. The volume fraction of each phase was determined using a Clemex image analysis system. All grain sizes were measured as equivalent area diameter (EQAD) using Jeffries method. ${ }^{39}$ Volumetric grain sizes, which are required for developing the microstructure evolution models, were obtained by multiplying the measured EQAD with a factor of 1.2. ${ }^{40)}$

\section{Results}

\subsection{Austenite Conditioning}

\subsubsection{Austenite Grain Growth}

Table 2 gives an overview of the reheat conditions and the resulting austenite grain sizes for both steels. In all cases a heating rate of $5^{\circ} \mathrm{C} / \mathrm{s}$ has been employed to reach a designated austenitizing temperature. This temperature has been varied and suitable holding times have been employed to obtain well spaced austenite grain sizes. In particular, three grain sizes have been established in the range of 15 to $35 \mu \mathrm{m}$ as this is the range that is expected at the exit of the finishing mill. Thus, this selection provides a vehicle to quantify the effect of the initial austenite grain size on the phase transformation kinetics during run-out table cooling conditions. In addition, a larger austenite grain size similar to that resulting from reheating before hot rolling was included in the study with the goal to have an additional suitable start condition for quantifying constitutive and recrystallization behaviour of austenite.

\subsubsection{Constitutive Behaviour}

The stress-strain behaviour of austenite was experimentally investigated by a series of uniaxial compression tests. The deformation temperature was varied from 850 to $1100^{\circ} \mathrm{C}$, the strain rate from 0.1 to $10 \mathrm{~s}^{-1}$ and the initial austenite grain sizes shown in Table 2 were employed. The flow stress displays the generally accepted trends of increasing with decreasing temperature $\left(T_{\text {def }}\right)$ and increasing strain rate $(\dot{\varepsilon})$. At the highest deformation temperature and the lowest strain rates, there is some indication of dynamic recrystallization by observing a peak in the flow stress

Table 2. Schedule of the heat treatment and resulting austenite grain size.

\begin{tabular}{lcccc}
\hline Steel & Reheating rate $\left({ }^{\mathbf{0}} \mathbf{C} / \mathbf{s}\right)$ & Soaking temperature $\left({ }^{\mathbf{0}} \mathbf{C}\right)$ & Soaking time $(\mathbf{s})$ & $\mathbf{d}_{\text {vol }}[\boldsymbol{\mu} \mathbf{m}]$ \\
\hline L-DP & 5 & 950 & 120 & 17 \\
\cline { 2 - 5 } & 5 & 1000 & 120 & 24 \\
\cline { 2 - 5 } & 5 & 1150 & 300 & 32 \\
\hline \multirow{nyyyy}{*}{ Mo-DP } & 5 & 1200 & 900 & 310 \\
\cline { 2 - 5 } & 5 & 950 & 150 & 16 \\
\cline { 2 - 5 } & 5 & 1050 & 780 & 24 \\
\cline { 2 - 5 } & 5 & 1100 & 120 & 32 \\
\hline
\end{tabular}


curve. However, as discussed previously ${ }^{32)}$ this, while potentially being of some significance for rough rolling, does not affect the final microstructure in the as coiled hot band. As a result, modeling of the flow stress curves emphasizes the cases without dynamic recrystallization. Then, the deformation behaviour of austenite is in a first approximation independent of grain size.

As described in detail elsewhere, ${ }^{38)}$ the Kocks-Mecking (KM) approach offers a well-established model to predict the flow stress evolution during deformation of austenite. ${ }^{41)}$ The advantage of the Kocks-Mecking model is its physical basis such that a reliable extrapolation can be made from laboratory tests with lower strain rates to the higher strain rates of finish rolling. In this model, the flow stress, $\sigma$, is represented in terms of two components:

$$
\sigma=\sigma_{\mathrm{y}}(T, \dot{\varepsilon})+\sigma_{\mathrm{d}}(T, \dot{\varepsilon}, \varepsilon)
$$

where the first term is the yield stress, $\sigma_{\mathrm{y}}(T, \dot{\varepsilon})$, and the second term, $\sigma_{\mathrm{d}}(T, \dot{\varepsilon}, \varepsilon)$, accounts for the contribution from work hardening. The temperature and strain rate dependence of the yield stress can be written as:

$$
\frac{\sigma_{\mathrm{y}}}{\mu}=\frac{\sigma_{\mathrm{y} 0}}{\mu_{0}}\left\{1-\left(\frac{k T}{g_{0}^{\prime} \mu b^{3}} \ln \frac{\dot{\varepsilon}_{0}^{\prime}}{\dot{\varepsilon}}\right)^{1 / 2}\right\}^{2}
$$

Here, $\mu$ is the temperature dependent shear modulus, ${ }^{42)} \mu_{0}$ is the shear modulus at $0 \mathrm{~K}, k$ is the Boltzmann constant, $T$ is the absolute temperature (in $\mathrm{K}$ ) and $b$ is the magnitude of the Burgers vector. The latter can be expressed with the lattice parameter, $a_{\gamma}$, i.e. $b=\sqrt{2} a_{\gamma} / 2$, where the temperature dependence of $a_{\gamma}$ is taken from Onink et al. ${ }^{43)}$ The normalizing strain rate can be postulated as $\dot{\varepsilon}_{0}^{\prime}=10^{7} \mathrm{~s}^{-1}$ and $g_{0}^{\prime}$ and $\sigma_{\mathrm{y} 0}$, the extrapolation of the yield stress to $0 \mathrm{~K}$, are employed as fit parameter; their values are summarized in Table 3.

The work hardening behaviour of austenite is assumed to follow the Voce equation, i.e.

$$
\sigma_{\mathrm{d}}=\sigma_{\mathrm{v}}\left(1-\exp \left(-\frac{\theta_{0}}{\sigma_{\mathrm{v}}} \varepsilon\right)\right)
$$

where $\varepsilon$ is the true strain, $\theta_{0}$ the initial work hardening rate that can be approximated by $\mu / 30$ and $\sigma_{\mathrm{v}}$ is the scaling stress as defined by Kocks and Mecking. ${ }^{41)}$ The temperature and strain rate dependence of the scaling stress can be described by:

$$
\frac{\sigma_{\mathrm{v}}}{\mu}=\frac{\sigma_{\mathrm{v} 0}}{\mu_{0}}\left\{1-\left(\frac{k T}{g_{0} \mu b^{3}} \ln \frac{\dot{\varepsilon}_{0}}{\dot{\varepsilon}}\right)^{1 / 2}\right\}^{2}
$$

Table 3. Parameters describing constitutive behaviour.

\begin{tabular}{lcccc}
\hline Steel & $\sigma_{y 0}, \mathrm{MPa}$ & $\sigma_{v 0}, \mathrm{MPa}$ & $g_{0}$ & $g_{0}^{\prime}$ \\
\hline L-DP & 448 & 1465 & 1.0 & 1.0 \\
\hline Mo-DP & 415 & 1221 & 1.0 & 1.0 \\
\hline
\end{tabular}

where the normalizing strain rate is again taken as $\dot{\varepsilon}_{0}=$ $10^{7} \mathrm{~s}^{-1}, \sigma_{\mathrm{v} 0}$ is the scaling stress extrapolated to $0 \mathrm{~K}$ that together with $g_{0}$ is used as adjustable parameter, as shown in Table 3. As indicated in the Table the values for $g_{0}^{\prime}$ and $g_{0}$, respectively, are 1 for both steels, as also observed previously for a TRIP steel. ${ }^{38)}$ This appears to suggest that $g_{0}^{\prime}=$ $g_{0}=1$ may be assumed as a universal relationship independent of steel chemistry such that only the extrapolations of yield and scaling stresses to $0 \mathrm{~K}$ remain as chemistry dependent parameters.

\subsubsection{Static Recrystallization}

Static recrystallization is the main softening mechanism between roll stands. The recrystallization kinetics has been quantified with double-hit tests following established procedures. ${ }^{38)}$ The fraction recrystallized can be described using the Johnson-Mehl-Avrami-Kolmogorov (JMAK) approach $^{32)}$

$$
f_{\text {rex }}=1-\exp \left(-0.693\left(\frac{t}{t_{50}}\right)^{n}\right)
$$

where $n$ is the Avrami exponent and $t_{0.5}$ is the time for $50 \%$ recrystallization that can be represented by

$$
t_{50}=A d_{\gamma}^{c_{1}} \mathcal{\varepsilon}^{c_{2}} \dot{\boldsymbol{\varepsilon}}^{c_{3}} \exp \left(\frac{Q_{\text {rex }}}{R T}\right)
$$

Here, $A, c_{1}, c_{2}, c_{3}$ and $Q_{\text {rex }}$ are steel grade specific parameters that have to be determined from experimental studies. These parameters are summarized together with the values of $n$ for the present steels in Table 4. Figure 1(a) illustrates the quality of the fit using laboratory results for essentially identical deformation conditions for both steels. Typical recrystallization times are similar in both steels while it appears that in the Mo-DP steel the recrystallization process once initiated is stretched over a longer time interval. These relatively minor differences may be associated with the way various alloying elements, i.e. here Si vs. Mo, affect recrystallization. Figure 1(b) shows the predicted recrystallization kinetics that may be expected in the final finishing stands with deformation temperature of $900^{\circ} \mathrm{C}$ at a strain rate of $100 \mathrm{~s}^{-1}$. For both steels the time for $50 \%$ recrystallization is in the present case $3 \mathrm{~s}$ and the time for completion of recrystallization may be as high as $10 \mathrm{~s}$. Clearly, this indicates that for both steels complete recrystallization cannot be expected in the finishing mill. Instead, both grades will be rolled under conditions of partial or no recrystallization in the later stands of the finish mill train. As a result, a pancaked austenite microstructure will enter the run-out table and constitute the initial austenite microstructure for the decomposition of austenite. This behaviour is similar to that recently observed for a TRIP steel ${ }^{38)}$ and confirms a general trend for AHSS where, because of the increased alloying levels, recrystallization is sufficiently delayed such that its completion during finish rolling in a strip mill may not occur.

An important characteristic of recrystallization is the re-

Table 4. Range of experimental conditions and parameters describing static recrystallization.

\begin{tabular}{ccccccccccc}
\hline Steel & $\varepsilon$ & $\begin{array}{c}T_{\text {def }} \\
\left({ }^{\circ} \mathrm{C}\right)\end{array}$ & $\begin{array}{c}d \varepsilon / d t \\
\left(\mathrm{~s}^{-1}\right)\end{array}$ & $\begin{array}{c}\mathrm{d}_{0} \\
(\mu \mathrm{m})\end{array}$ & $\begin{array}{c}A \\
\left(\mathrm{~s}^{1+c_{3}} \mu \mathrm{m}^{-c_{1}}\right)\end{array}$ & $c_{l}$ & $c_{2}$ & $c_{3}$ & $\begin{array}{c}Q_{\text {rex }} \\
(\mathrm{kJ} / \mathrm{mol})\end{array}$ & $n$ \\
\hline L-DP & 0.2 to & 900 to & 0.1 to & 17 to & $3.4 \times 10^{-7}$ & 0.23 & -2.85 & -0.14 & 121 & 2 \\
& 0.5 & 1100 & 10 & 310 & & & & & & \\
\hline Mo-DP & 0.1 to & 900 to & 0.1 to & 16 to & $1.58 \times 10^{-13}$ & 0.67 & -3.99 & -0.18 & 235 & 1 \\
& 0.3 & 1100 & 10 & 32 & & & & & & \\
\hline
\end{tabular}


a)

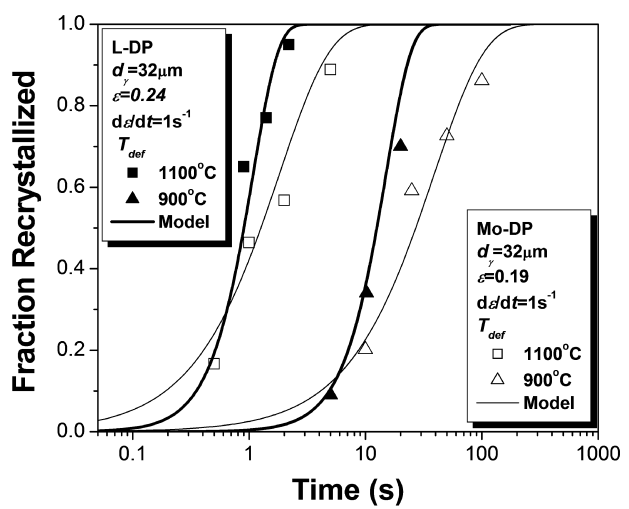

b)

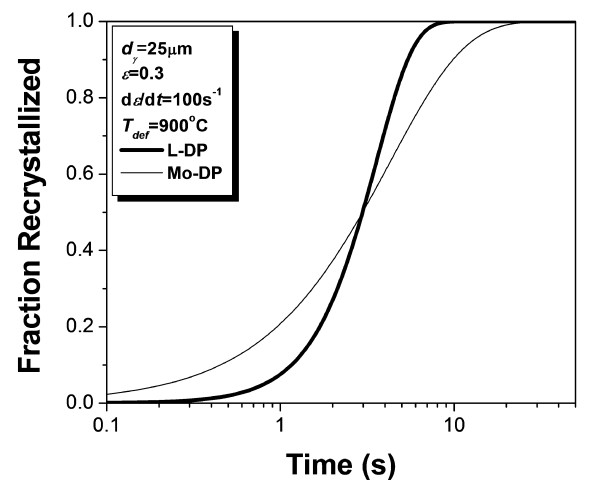

Fig. 1. Comparison of static recrystallization kinetics: (a) the experimental and calculated static recrystallization kinetics showing the effect of deformation temperature; (b) the predicted static recrystallization kinetics for the L-DP and Mo-DP steels for typical conditions in later finish mill stands with a rolling temperature of $900^{\circ} \mathrm{C}$, a strain of 0.3 at a strain rate of $100 \mathrm{~s}^{-1}$, and an initial austenite grain size of $25 \mu \mathrm{m}$.

sulting grain size; grain refinement from stand to stand takes place as long as complete recrystallization is possible. Revealing the recrystallized grain size for the present low carbon steels proved to be a challenging task; estimates of the grain sizes indicated that they are similar to those observed in steels with higher carbon levels, i.e. 0.17 and $0.20 \mathrm{wt} \%$, respectively. For these steels, i.e. a plain carbon $0.17 \mathrm{wt} \% \mathrm{C}-0.74 \mathrm{wt} \% \mathrm{Mn}$ steel and a Mo-TRIP steel, the recrystallized grain size is described by ${ }^{38,45)}$

$$
d_{\text {rex }}=B d_{0}^{z} \varepsilon^{-p} \exp \left(-\frac{Q_{\mathrm{gx}}}{R T}\right)
$$

The parameters $B, z, p$ and $Q_{\mathrm{gx}}$ are very similar for these previously studied grades, i.e. $B=100 \mu \mathrm{m}^{2 / 3}, z=1 / 3, p=$ 0.37 and $Q_{\mathrm{gx}}=28 \mathrm{~kJ} / \mathrm{mol}$ for the $0.17 \mathrm{wt} \%$ carbon steel and $B=65 \mu \mathrm{m}^{2 / 3}, z=1 / 3, p=0.7$ and $Q_{\mathrm{gx}}=27 \mathrm{~kJ} / \mathrm{mol}$ for the TRIP steel. Analyzing these data suggests that the predicted grain sizes are usually within $10-20 \%$ for typical hot strip rolling conditions with strains per pass in the finishing mill of $0.2-0.4$. Thus, it is reasonable to adopt these previously established relationships for the recrystallized grain size also for the present DP steels with the parameters for the lower carbon grade, i.e. $0.17 \mathrm{wt} \%$, being selected for both DP grades. However, further studies are required to quantify recrystallized grain sizes for lower carbon steels more accurately. Such investigations may include to employ novel characterization techniques such as laser ultrasonics. $^{46,47)}$ a)

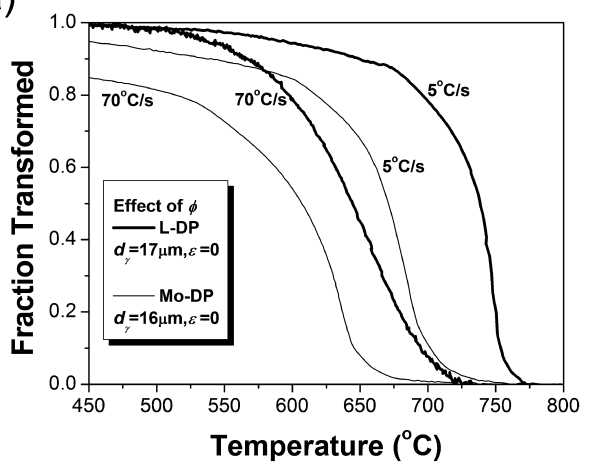

b)

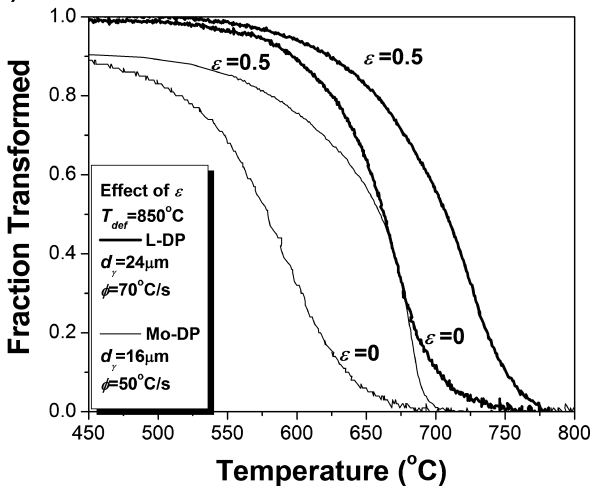

Fig. 2. Experimental results showingthe effects of: (a) cooling rate and (b) pancaking on continuous cooling transformation behaviour for the L-DP and Mo-DP steels.

\subsection{Austenite-to-ferrite Transformation}

3.2.1. Experimental Observations

The austenite decomposition on the run-out table is a critical metallurgical tool to tailor the final microstructure of hot-rolled AHSS. Figure 2 shows representative examples of results from continuous cooling tests to quantify the austenite decomposition kinetics in the present steels. Figure 2(a) gives an indication of the role of cooling rate. As the cooling rate increases the transformation is shifted to lower temperature consistent with the vast experimental body on this phase transformation. Comparing the two steels it is evident that for comparable conditions in terms of initial austenite microstructure and cooling rate the transformation occurs at a lower temperature region in the Mo-DP steel. Thus, to have the transformation taking place in a similar temperature range a much lower cooling rate must be applied for the Mo-DP steel, i.e. in the shown example $5^{\circ} \mathrm{C} / \mathrm{s}$ vs. $70^{\circ} \mathrm{C} / \mathrm{s}$. This behaviour can be associated with the addition of Mo as an alloying element; Mo is known to strongly delay the ferrite formation and its role is much more pronounced than those of other alloying elements, i.e. $\mathrm{Mn}$ and $\mathrm{Si}$, of interest here. Figure 2(b) indicates the effect of a pancaked austenite microstructure on the transformation kinetics. The results confirm for both steels the generally accepted view that pancaking accelerates the austenite decomposition. As a result, the transformation is shifted to a higher temperature range during continuous cooling. Taking the $50 \%$ transformed mark, this shift amounts to approximately $50^{\circ} \mathrm{C}$ in the L-DP steel and $100^{\circ} \mathrm{C}$ in the Mo-DP steel for the example shown in Fig. 2(b).

Figure 3 displays a selection of relevant microstructures from the transformation tests shown in Fig. 2. Figures 3(a) and 3(c) show the microstructures resulting when transforming from a fine equiaxed, i.e. undeformed, austenite 

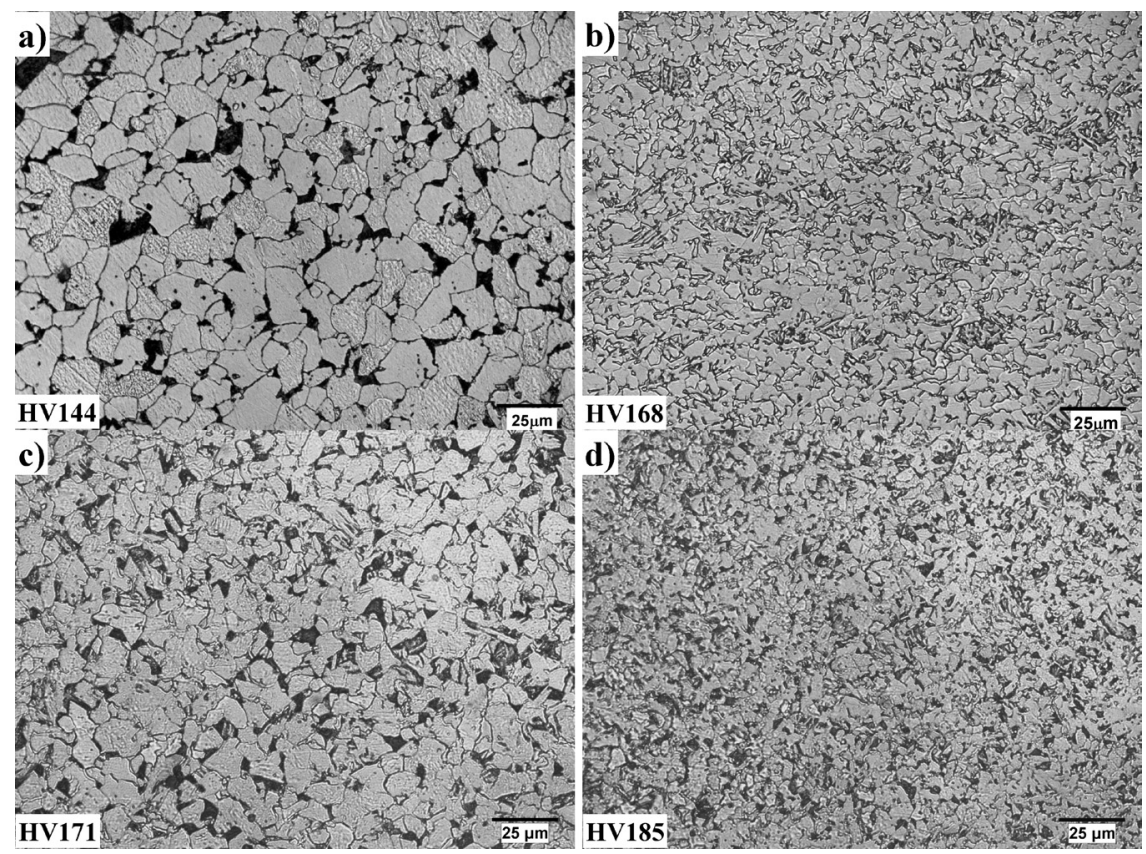

Fig. 3. Microstructure produced during continuous cooling transformation in L-DP and Mo-DP steels with different austenite conditions and cooling rates: a) L-DP, $d_{\gamma}=17 \mu \mathrm{m}, \varepsilon=0, \phi=5^{\circ} \mathrm{C} / \mathrm{s} ;$ b) L-DP, $d_{\gamma}=24 \mu \mathrm{m}, \varepsilon=0.5$, $\phi=70^{\circ} \mathrm{C} / \mathrm{s}$; c) Mo-DP: $d_{\gamma}=16 \mu \mathrm{m}, \varepsilon=0, \phi=5^{\circ} \mathrm{C} / \mathrm{s}$; d) Mo-DP: $d_{\gamma}=16 \mu \mathrm{m}, \varepsilon=0.5, \phi=50^{\circ} \mathrm{C} / \mathrm{s}$.

microstructure at a cooling rate of $5^{\circ} \mathrm{C} / \mathrm{s}$. In the L-DP steel, Fig. 3(a), a classical ferrite-pearlite microstructure is observed with a polygonal ferrite grain structure that is characterized by a fraction of 0.91 and a mean grain size of $11.5 \mu \mathrm{m}$. In the Mo-DP steel, Fig. 3(c), also a predominantly polygonal ferrite microstructure is recorded. However, the fraction is with 0.8 somewhat lower as is the mean grain size $(7 \mu \mathrm{m})$. Further, there are some indications for acicular ferrite and the second transformation product is bainite rather than pearlite. These differences in transformation features are consistent with the effect of Mo on the transformation and the associated lower transformation temperature as compared to the L-DP steel. At the higher cooling rate of $50-70^{\circ} \mathrm{C} / \mathrm{s}$, the resulting microstructures are predominantly non-polygonal in nature and thus not useful for a DP steel product. However, as illustrated in Figs. 3(b) and 3(d), applying deformation to austenite without recrystallization, i.e. having a pancaked austenite as initial microstructure, the formation of polygonal ferrite can be extended to these higher cooling rates that are similar to those of accelerated cooling conditions on the run-out table. For both steels a predominantly polygonal ferrite microstructure is observed with a ferrite fraction of approximately 0.7 . Further, due to the higher cooling rates, a tremendous grain refinement can be achieved as compared to the slow cooling conditions shown in Figs. 3(a) and 3(c), respectively. The mean ferrite grain size is $6.5 \mu \mathrm{m}$ in the L-DP steel and $3.5 \mu \mathrm{m}$ in the Mo-DP steel. The second transformation product is in both cases primarily bainite. This suggests that a simple continuous cooling path is not suitable for the investigated steels to develop the desired ferrite-martensite dual-phase structure. Instead stepped cooling regimes are required that martensite forms as the second transformation product in conjunction with polygonal ferrite, as discussed in more detail in Sec. 3.2.3.

\subsubsection{Austenite-to-ferrite Transformation Model}

Before dealing with martensite formation the findings for ferrite formation will be rationalized. The austenite-to-fer- rite transformation in the investigated steels follows the well established patterns for low carbon steels. Models for this transformation had first been developed for plain carbon steels and subsequently applied to microalloyed steels. ${ }^{32,48,49)}$ These models remain applicable to AHSS with higher alloying contents. ${ }^{33,35,38)}$ Following the previously established approach the austenite-to-ferrite transformation kinetics is described with a model consisting of three submodels, i.e. (i) transformation start, (ii) ferrite growth, (iii) ferrite grain size.

The transformation start temperature is predicted by considering early growth of corner ferrite nucleated at a temperature $T_{\mathrm{N}}$. Early growth is assumed to be controlled by carbon diffusion in austenite and the evolution of the radius, $r_{\alpha}$, of the ferrite grain is described using steady-state conditions, i.e..$^{32,48)}$

$$
\frac{d r_{\alpha}}{d T} \frac{d T}{d t}=D_{\mathrm{C}} \frac{c_{\mathrm{eq}}^{\gamma}-c^{0}}{c_{\mathrm{eq}}^{\gamma}-c_{\mathrm{eq}}^{\alpha}} \frac{1}{r_{\alpha}}
$$

where $D_{\mathrm{C}}$ is the carbon diffusivity in austenite, ${ }^{51)} c^{0}$ is the bulk concentration of carbon and the equilibrium concentrations of carbon in ferrite, $c_{\mathrm{eq}}^{\alpha}$, and austenite, $c_{\mathrm{eq}}^{\gamma}$, respectively, have been determined from Thermo-Calc using the Fe2000 data base and assuming ortho-equilibrium.

The carbon concentration profile around the growing ferrite grain is given by

$$
c(r)=\left(c_{\mathrm{eq}}^{\gamma}-c^{0}\right)\left(\frac{r_{\alpha}}{r}\right)+c^{0} .
$$

Ferrite nucleation cannot take place where ferrite covers the austenite grain boundary but also in the vicinity of the growing ferrite grain because of the enhanced level of carbon there. Introducing, a limited carbon concentration, $c^{*}$, above which ferrite nucleation is inhibited, the limiting radius, $r^{*}$, for nucleation can be written as a function of the ferrite radius, i.e. 


$$
r^{*}=\frac{c_{\mathrm{eq}}^{\gamma}-c^{0}}{c^{*}-c^{0}} r_{\alpha}
$$

Ferrite nucleation at grain boundaries ceases when the entire austenite grain boundary area is covered with a carbon level above $c^{*}$ which is equivalent to $2 r^{* 2}=d_{\text {eff. }}^{\gamma 2}{ }^{48)}$ Here, the effective austenite grain size ${ }^{51)}$

$$
d_{\mathrm{eff}}^{\gamma}=d_{\gamma} \exp (-\varepsilon)
$$

is introduced to account for the effect of pancaking on the transformation kinetics; $\varepsilon$ is the strain applied under no-recrystallization conditions. Nucleation site saturation conditions at the austenite grain boundary can then be written as

$$
r_{\alpha} \geq \frac{c^{*}-c^{0}}{c_{\mathrm{eq}}^{\gamma}-c^{0}} \frac{d_{\mathrm{eff}}^{\gamma}}{\sqrt{2}}
$$

The condition of nucleation site saturation is assumed to coincide with measurable transformation start. Then, the transformation start temperature, $T_{\mathrm{S}}$, under continuous cooling conditions can be obtained by integrating the differential Eq. (8) until condition (12) is reached. For cooling at a constant rate, $\varphi$, this calculation procedure can be expressed in the following integral form ${ }^{32,48)}$

$$
\frac{c^{*}-c^{0}}{c_{\mathrm{eq}}^{\gamma}-c^{0}}=\frac{2}{\varphi^{1 / 2} d_{\mathrm{eff}}^{\gamma}} \sqrt{\int_{T_{\mathrm{S}}}^{T_{\mathrm{N}}} \frac{c_{\mathrm{eq}}^{\gamma}-c^{0}}{c_{\mathrm{eq}}^{\gamma}-c_{\mathrm{eq}}^{\alpha}}} d T
$$

In this analysis, $T_{\mathrm{N}}$ and $c^{*}$ serve as adjustable parameters as shown in Table 5. Figure 4 illustrates the quality of this model approach by comparing its results with the experimental data where transformation start has been taken as the point of $5 \%$ transformed. As evident from this Figure, the start of ferrite formation requires an undercooling that is approximately $20-30^{\circ} \mathrm{C}$ higher in the Mo-DP steel than in the L-DP steel. This is a further illustration of the kinetic effect of Mo in delaying the ferrite formation. As discussed in the literature, it is believed that this can be attributed to a strong solute drag effect of Mo. ${ }^{52,53)}$

Subsequent ferrite growth can be described with the JMAK theory even though more fundamentally based approaches are available in terms of a mixed-mode model that takes both interface reaction and long range carbon diffusion into account. ${ }^{53,54)}$ However, when developing a process model for industrial application it appears to be preferable to implement the numerically less demanding JMAK approach in combination with the additivity rule ${ }^{55)}$ for the non-isothermal transformation conditions. Here, the fraction, $f_{\alpha}$, of ferrite formed is described by

$$
\frac{f_{\alpha}}{f_{\alpha}^{\text {eq }}}=1-\exp \left(-b_{\alpha} \frac{t^{n_{\alpha}}}{\left(d_{\text {eff }}^{\gamma}\right)^{m}}\right) \ldots
$$

where $n_{\alpha}$ is the Avrami-exponent, $m$ the grain size exponent, $b_{\alpha}$ a rate parameter and the equilibrium ferrite fraction is given by

$$
f_{\alpha}^{\mathrm{eq}}=\frac{c_{\mathrm{eq}}^{\gamma}-c^{0}}{c_{\mathrm{eq}}^{\gamma}-c_{\mathrm{eq}}^{\alpha}}
$$

The Avrami-exponent, $n_{\alpha}$, is for the ferrite reaction approximately $1{ }^{56)}$ Indeed, based on the experimental data, $n_{\alpha}=1$ has been confirmed for both investigated steels. In the present study of continuous cooling transformation, the carbon redistribution during ferrite transformation is considered to affect the transformation kinetics since the un-transformed
Table 5. Parameters describing austenite-to-ferrite transformation.

\begin{tabular}{lcccccc}
\hline Steel & $B_{0}$ & $\begin{array}{c}B_{I} \\
\left({ }^{\circ} \mathrm{C} / \mathrm{s}\right)\end{array}$ & $\begin{array}{c}B_{2} \\
(\mathrm{wt} / \%)^{-1}\end{array}$ & $m$ & $\begin{array}{c}T_{N} \\
\left({ }^{\circ} \mathrm{C}\right)\end{array}$ & $c^{*} / \mathrm{c}^{0}$ \\
\hline L-DP & 6.33 & 0.036 & -8.1 & 3.78 & 805 & 1.6 \\
\hline Mo-DP & -2.5 & 0.05 & -14.5 & 1.73 & 732 & 1.5 \\
\hline
\end{tabular}

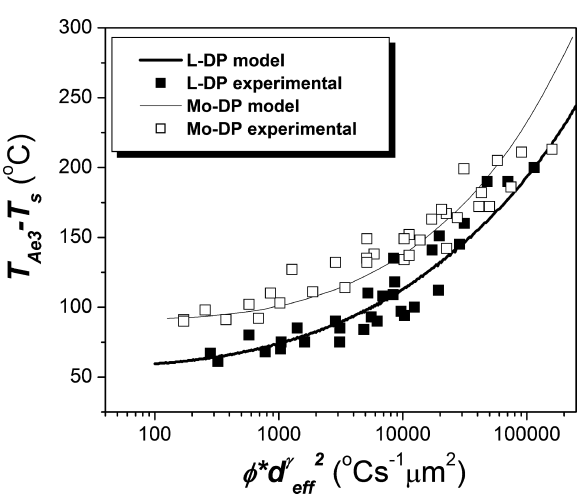

Fig. 4. Comparison of calculated and measured results for the transformation start temperature, $T_{\mathrm{s}}$, as a function of cooling rate and effective austenite grain size.

austenite is stabilized due to carbon enrichment. The rate parameter $b_{\alpha}$ is then expressed as a separable function of temperature $(T)$ and fraction of ferrite transformed $\left(f_{\alpha}\right)$ in the following form

$$
b_{\alpha}=\exp \left\{B_{0}+B_{1}\left(T_{\mathrm{Ae} 3}-T\right)+B_{2} \frac{c^{0}}{1-f_{\alpha}}\right\}
$$

The parameters $B_{0}, B_{1}, B_{2}$ and the grain size exponent $m$ are listed in Table 5, as determined from the present continuous cooling transformation data.

It is generally accepted that the ferrite grain size is determined in the early transformation stages such that it can be described as a function of the transformation start temperature. ${ }^{58)}$ Here, the following relationship has been adopted for the EQAD of the ferrite grain size

$$
d_{\alpha}=\left(f_{\alpha} \exp \left(C\left(d_{\mathrm{eff}}^{\gamma}\right)^{q}-E / T_{\mathrm{s}}\right)\right)^{1 / 3}
$$

In a first approximation, $C=30 \mu \mathrm{m}^{-q}$ and $q=0.08$ can be employed for both steels such that just $E$ remains as a fitting parameter that depends on steel chemistry with $E=32000 \mathrm{~K}$ and $E=30000 \mathrm{~K}$ being obtained for the L-DP and the Mo-DP steels, respectively.

\subsubsection{Remaining Austenite Transformation Behaviour}

The evaluation of the formation of the second transformation product beside polygonal ferrite has been focused on the desired ferrite-martensite dual-phase microstructures. For this purpose, a prescribed polygonal ferrite fraction was formed in dedicated transformation tests by applying a slow cooling rate to a designated temperature before rapid cooling to room temperature. In cases to obtain ferrite fractions of 0.8 and higher the slow cooling step was supplemented with an isothermal hold at a designated temperature before rapid cooling. The rapid cooling step to room temperature was applied with systematically varied cooling rates to determine the critical cooling condition that all remaining austenite transforms to martensite. Further, this approach permits also to determine the critical cooling rates for bainite transformation, i.e. the condition required to avoid the formation of pearlite. However, no detailed kinetic studies have been performed for pearlitic and bainitic 


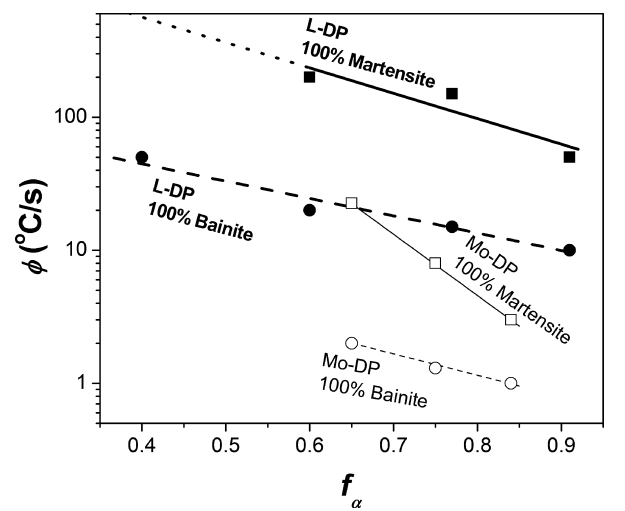

Fig. 5. Comparison of calculated (lines) and measured (symbols) critical cooling rates for martensite formation and bainite formation as function of ferrite fraction for the L-DP and Mo-DP steels.

Table 6. Parameters describing the critical cooling rates for remaining austenite-to-martensite/bainite transformation after ferrite formation.

\begin{tabular}{lccc}
\hline Steel & Transformation product & $a$ & $b$ \\
\hline \multirow{2}{*}{ L-DP } & Martensite & 8.1 & -4.4 \\
\cline { 2 - 4 } & Bainite & 5.0 & -3.0 \\
\hline \multirow{2}{*}{ Mo-DP } & Martensite & 10.0 & -10.6 \\
\cline { 2 - 4 } & Bainite & 3.1 & -3.7 \\
\hline
\end{tabular}

transformation products. In particular, the description of the bainite reaction for run-out table cooling requires further work. ${ }^{49)}$ Figure 5 shows the results for the critical cooling rates of bainite and martensite formation in the present steels. These cooling rates tend to decrease with increasing ferrite fraction since the associated increase of carbon concentration in the remaining austenite leads to higher stability of the austenite phase. Further, the critical cooling rates are at least an order of magnitude larger in the L-DP steel as compared to the Mo-DP steel further illustrating the strong delaying effect of Mo on the austenite decomposition kinetics. For example, at a ferrite fraction of 0.85 the critical cooling rate amounts to approximately $100^{\circ} \mathrm{C} / \mathrm{s}$ in the L-DP steel whereas it is just $3^{\circ} \mathrm{C} / \mathrm{s}$ in the Mo-DP steel. In detail, the critical cooling rate can be written as:

$$
\phi\left({ }^{\circ} \mathrm{C} / \mathrm{s}\right)=e^{\left(a+b f_{\alpha}\right)}
$$

with the parameters $a$ and $b$ given in Table 6 for both the bainite and martensite transformations. Alternatively, these cooling rates can, in case of the martensite condition, be translated into a cooling time between the ferrite stop temperature and the martensite start temperature. The latter can be estimated using established relationships taking into account the carbon enrichment of remaining austenite, as recently illustrated for a TRIP steel. ${ }^{38)}$

\subsection{Simulations of Industrial Hot Rolling Conditions}

3.3.1. Transformation Kinetics during Stepped Run-out Table Cooling

In order to evaluate the predictive capabilities of the above delineated model laboratory simulations of actual processing paths of hot strip rolling have been performed. Given the critical importance of run-out table cooling, a first series of validation tests just emphasized stepped cooling regimes. These tests were conducted on the Gleeble 3500 where a suitable initial austenite microstructure was established as in the CCT tests. Figure 6(a) indicates the a)

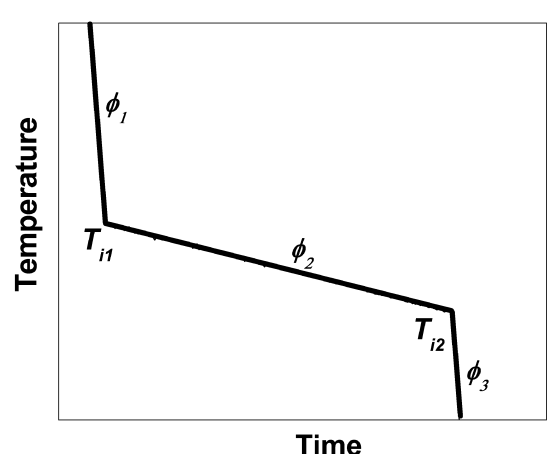

b)

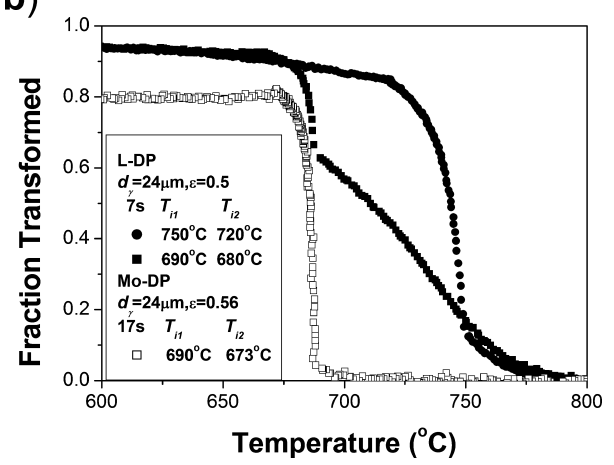

Fig. 6. Schematic illustration of run out table stepped cooling simulations (a) and the resulting transformation kinetics for the L-DP and Mo-DP steels (b), respectively.

simulated cooling path where an initial cooling rate, $\phi_{1}$, of approximately $50^{\circ} \mathrm{C} / \mathrm{s}$ was employed until the cooling interruption temperature, $T_{\mathrm{i} 1}$. Between this temperature and a second interruption temperature, $T_{\mathrm{i} 2}$, the specimen is slowly cooled at a rate $\phi_{2}$ that falls in the range of $1-20^{\circ} \mathrm{C} / \mathrm{s}$. Finally, another fast cooling step is executed with a rate $\phi_{3}$ of $50^{\circ} \mathrm{C} / \mathrm{s}$ such that predominantly martensite is formed as the secondary transformation product. The detailed parameters of these stepped cooling tests are indicated in Table 7.

Figure 6(b) shows examples for the resulting transformation kinetics for selected conditions of the interruption temperatures. Figure 7 gives examples of the resulting microstructures that are indeed of the anticipated ferritemartensite combination. Table 7 provides the results of these tests in terms of polygonal ferrite fraction and ferrite grain size including a comparison of measured and predicted values. This comparison shows that there is an excellent agreement between model predictions and the experimental observations in both the L-DP and Mo-DP steels.

Evaluating the results in more detail, it is evident that for the L-DP steel, it was possible to employ a slow cooling period of $7 \mathrm{~s}$ that is realistic for run-out table processing. Moreover, the temperature interval for this slow cooling step can be varied over the rather wide range of 750 to $610^{\circ} \mathrm{C}$ without any significant variation in the ferrite fraction of approximately 0.90 . This illustrates clearly that robust processing paths can be designed for the L-DP steel that is, thus, suitable for hot strip mill conditions. In contrast, for the Mo-DP steel it is found that even for a much longer slow cooling period of up to $85 \mathrm{~s}$ the ferrite fraction cannot be increased beyond 0.82 . Further, a processing window to reach a ferrite fraction of 0.80 with a slow cooling period of under $10 \mathrm{~s}$ has been established for the temperature range of approximately 700 to $650^{\circ} \mathrm{C}$. However, additional investigations are required to examine the ro- 
Table 7. Measured and predicted ferrite fractions and grain sizes for stepped cooling conditions.

\begin{tabular}{|c|c|c|c|c|c|c|c|c|c|c|c|c|}
\hline \multirow[b]{2}{*}{ Steel } & \multicolumn{2}{|c|}{ Austenite } & \multicolumn{5}{|c|}{ Parameters on ROT cooling } & \multirow{2}{*}{$\begin{array}{c}\text { Time from } 850 \text { to } 600^{\circ} \mathbf{C} \\
t_{850 / 600} \\
(\mathrm{~s})\end{array}$} & \multicolumn{2}{|c|}{$f_{\alpha}$} & \multicolumn{2}{|c|}{$d_{\alpha}$} \\
\hline & $\begin{array}{c}d_{\gamma} \\
(\mu m)\end{array}$ & $\varepsilon_{r}$ & $\begin{array}{c}\phi_{1} \\
\left({ }^{\circ} \mathrm{C} / \mathrm{s}\right) \\
\end{array}$ & $\begin{array}{c}T_{i l} \\
\left({ }^{\circ} \mathrm{C}\right)\end{array}$ & $\begin{array}{c}\phi_{2} \\
\left({ }^{\circ} \mathrm{C} / \mathrm{s}\right)\end{array}$ & $\begin{array}{c}T_{i 2} \\
\left({ }^{\circ} \mathrm{C}\right)\end{array}$ & $\begin{array}{c}\phi_{3} \\
\left({ }^{\circ} \mathrm{C} / \mathrm{s}\right)\end{array}$ & & Pred. & Exp. & $\begin{array}{l}\text { Pred. } \\
(\mu \mathrm{m})\end{array}$ & $\begin{array}{c}\text { Exp. } \\
(\mu \mathrm{m})\end{array}$ \\
\hline L-DP & 24 & 0.5 & 50 & 750 & 4.3 & 720 & 50 & 11.4 & 0.9 & 0.89 & 8.3 & 6.5 \\
\hline L-DP & 24 & 0.5 & 50 & 690 & 2.9 & 670 & 50 & 11.6 & 0.92 & 0.92 & 8.4 & 6.5 \\
\hline L-DP & 17 & 0.5 & 50 & 750 & 4.3 & 720 & 50 & 11.4 & 0.9 & 0.9 & 6.7 & 6.7 \\
\hline L-DP & 17 & 0.5 & 50 & 750 & 20 & 610 & 50 & 9.2 & 0.91 & 0.92 & 6.7 & 6.0 \\
\hline L-DP & 17 & 0.5 & 50 & 690 & 1.3 & 680 & 50 & 11.8 & 0.92 & 0.9 & 6.7 & 6.0 \\
\hline L-DP & 17 & 0.5 & 50 & 690 & 11.4 & 610 & 50 & 10.4 & 0.92 & 0.93 & 6.7 & 6.0 \\
\hline L-DP & 32 & 0.5 & 50 & 690 & 1.3 & 680 & 50 & 11.8 & 0.9 & 0.91 & 7.9 & 8.7 \\
\hline Mo-DP & 24 & 0.56 & 50 & 690 & 1 & 673 & 50 & 21.7 & 0.82 & 0.80 & 6.0 & 5.2 \\
\hline Mo-DP & 24 & 0.57 & 50 & 690 & 1.3 & 680 & 50 & 11.8 & 0.78 & 0.80 & 6.0 & 6.0 \\
\hline Mo-DP & 24 & 0.55 & 50 & 660 & 1 & 650 & 50 & 14.8 & 0.81 & 0.82 & 5.1 & 4.8 \\
\hline Mo-DP & 16 & 0.56 & 50 & 720 & 4.5 & 630 & 50 & 23.2 & 0.83 & 0.81 & 5.6 & 5.8 \\
\hline Mo-DP & 16 & 0.56 & 50 & 700 & 1 & 683 & 50 & 21.7 & 0.78 & 0.83 & 4.5 & 4.5 \\
\hline Mo-DP & 16 & 0.57 & 50 & 690 & 1.3 & 680 & 50 & 11.8 & 0.81 & 0.80 & 4.1 & 4.0 \\
\hline Mo-DP & 16 & 0 & 50 & 700 & 1 & 615 & 50 & 88.3 & 0.86 & 0.81 & 7.8 & 8.6 \\
\hline
\end{tabular}
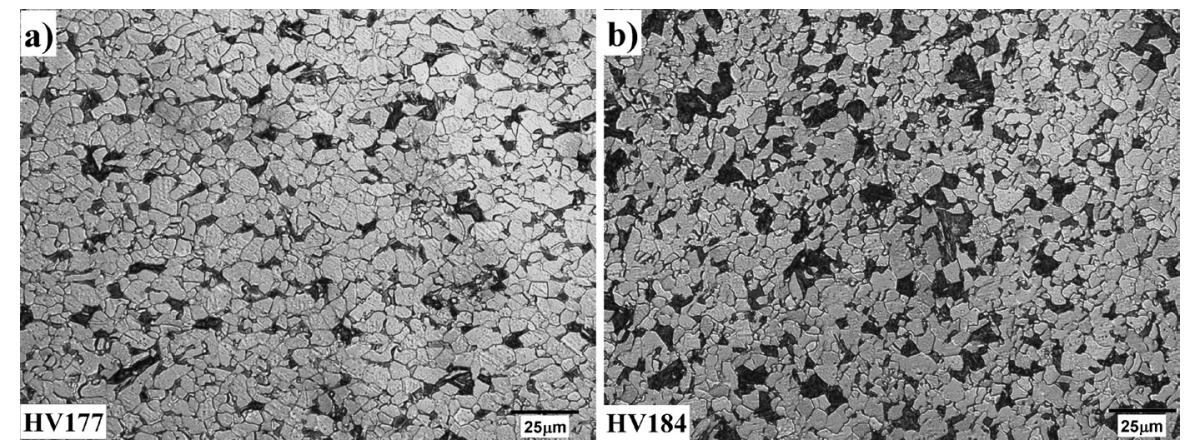

Fig. 7. Microstructures $(\mathrm{F}+\mathrm{M})$ obtained in the stepped cooling tests with slow cooling at $750-720^{\circ} \mathrm{C}$ for $7 \mathrm{~s}$ for the L-DP steel (a) and $690-673^{\circ} \mathrm{C}$ for $17 \mathrm{~s}$ (b) for the Mo-DP steel, respectively.

Table 8. Austenite microstructure evolution during simulated hot rolling.

\begin{tabular}{|c|c|c|c|c|c|c|c|c|c|c|}
\hline \multirow[b]{2}{*}{ Pass } & \multirow[b]{2}{*}{ Reduction (pct) } & \multirow[b]{2}{*}{$\varepsilon$} & \multirow[b]{2}{*}{$T_{\text {def }}\left({ }^{\circ} \mathrm{C}\right)$} & \multirow[b]{2}{*}{ Interpass Time (s) } & \multicolumn{3}{|c|}{ L-DP } & \multicolumn{3}{|c|}{ Mo-DP } \\
\hline & & & & & $\mathrm{d} \varepsilon / \mathrm{d} t\left(\mathrm{~s}^{-1}\right)$ & $d_{\gamma}(\mu \mathrm{m})$ & $\varepsilon_{r}$ & $\mathrm{~d} \mathcal{E} / \mathrm{d} t\left(\mathrm{~s}^{-1}\right)$ & $d_{\gamma}(\mu \mathrm{m})$ & $\varepsilon_{r}$ \\
\hline $\mathbf{R}$ & & 1.05 & 1150 & 10 & 1 & 98 & 0 & 1 & 98 & 0 \\
\hline F1 & 0.40 & 0.68 & 1100 & 4.8 & 1 & 58 & 0 & 1 & 58 & 0 \\
\hline F2 & 0.35 & 0.56 & 1060 & 3.1 & 1 & 40 & 0 & 1 & 40 & 0 \\
\hline F3 & 0.30 & 0.47 & 1020 & 2.2 & 1 & 32 & 0 & 1 & 32 & 0 \\
\hline F4 & 0.28 & 0.41 & 980 & 1.6 & 1 & & 0.08 & 1 & & 0.034 \\
\hline F5 & 0.25 & 0.37 & 950 & 1.2 & 1 & & 0.16 & 1 & & 0.11 \\
\hline F6 & 0.22 & 0.30 & 920 & 0.9 & 1 & & 0.20 & 1 & & 0.16 \\
\hline F7 & 0.18 & 0.26 & 895 & & 1 & & 0.46 & 1 & & 0.42 \\
\hline
\end{tabular}

bustness of this cooling route.

\subsubsection{Comprehensive Hot Rolling Simulation}

A second validation step of the model involves laboratory simulations of the entire process of a hot strip mill to produce DP steels using hot torsion testing. In these tests the samples were first reheated at $1200^{\circ} \mathrm{C}$ for $15 \mathrm{~min}$. Rough rolling was approximated as a single pass operation followed by a detailed finish mill schedule as given in Table 8. Apart from a lower strain rate of $1 \mathrm{~s}^{-1}$, all other processing parameters resemble those employed during finish rolling. As shown in an extensive study by Hall and Worobec $^{58)}$ the mechanical properties of hot band and material obtained from laboratory simulations with lower strain rates but otherwise equivalent processing conditions match reasonably well indicating that employing hot torsion simu- lation of industrial rolling with lower strain rates is an acceptable validation approach. Subsequently, stepped cooling regimes similar to the one described in the preceding section were employed to simulate run-out table cooling and coiling near room temperature, i.e. below the martensite start temperature. In detail, a slow cooling step was bracketed with fast cooling steps at surface cooling rates of $50^{\circ} \mathrm{C} / \mathrm{s}$. For the L-DP steel a slow cooling step was employed with a cooling rate of $1.4^{\circ} \mathrm{C} / \mathrm{s}$ from 690 to $680^{\circ} \mathrm{C}$, i.e. the slow cooling time amounts to $7 \mathrm{~s}$. For the Mo-DP steel, as indicated in Table 9, a variety of different slow cooling steps were investigated to further evaluate the robustness of run-out table cooling strategies for this grade.

Figure 8 gives the family of stress-strain curves observed in these torsion simulations. These curves are essentially identical for both steels confirming the results of sin- 
Table 9. Measured and predicted ferrite fraction and grain sizes for hot torsion simulations.

\begin{tabular}{lcccccc}
\hline Steel & $\begin{array}{c}\text { Slow cooling } \\
\text { time, } \mathrm{s}\end{array}$ & $\begin{array}{c}\text { Slow cooling } \\
\text { temperature } \\
\text { range, }{ }^{\circ} \mathrm{C}\end{array}$ & $\begin{array}{c}\text { Ferrite } \\
\text { fraction } \\
\text { (measured) }\end{array}$ & $\begin{array}{c}\text { Ferrite } \\
\text { fraction } \\
\text { (predicted) }\end{array}$ & $\begin{array}{c}\text { Ferrite grain } \\
\text { size, } \mu \mathrm{m} \\
\text { (measured) }\end{array}$ & $\begin{array}{c}\text { Ferrite grain } \\
\text { size, } \mu \mathrm{m} \\
\text { (predicted) }\end{array}$ \\
\hline L-DP & 7 & $690-680$ & 0.93 & 0.90 & 9.3 & 8.2 \\
\hline Mo-DP & 14 & $690-650$ & 0.73 & 0.76 & 8.0 & 8.9 \\
\hline Mo-DP & 20 & $720-630$ & 0.75 & 0.78 & 10.0 & 12.4 \\
\hline Mo-DP & 65 & $700-635$ & 0.83 & 0.83 & 10.1 & 10.4 \\
\hline
\end{tabular}

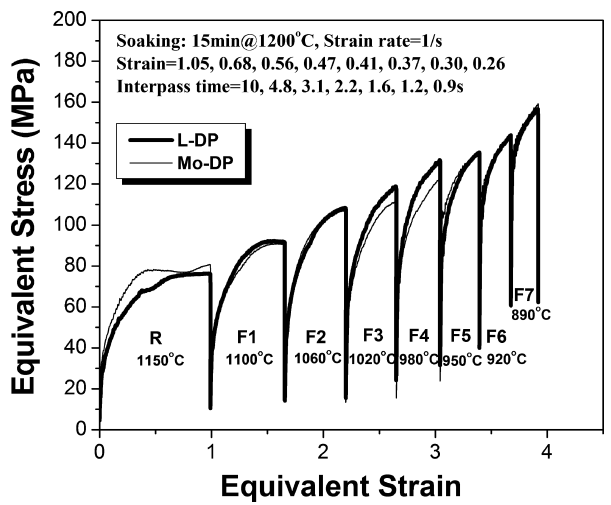

Fig. 8. Hot deformation responses in hot torsion simulation of the industrial rolling schedule for the L-DP and Mo-DP steels, respectively.

gle and double hit tests to quantify constitutive and recrystallization behaviour. After pass 4 of the finishing mill simulations, partial recrystallization is evident from the flow stress curves and this is consistent with the model predictions included in Table 8. The model predictions assume that reheating produces an austenite grain size of $290 \mu \mathrm{m}$ but the calculations are not sensitive to detail of this assumption. At the exit of the finishing mill, pancaked austenite with a grain size of $32 \mu \mathrm{m}$ and a retained strain of approximately 0.4 is expected. The resulting final microstructures after stepped cooling are shown in Fig. 9. For both steels ferrite-martensite microstructures are produced. In case of the L-DP steel the ferrite grain size is $9.2 \mu \mathrm{m}$ and the martensite fraction of 0.07 is obtained by employing a very realistic cooling path for run-out table processing. The relatively high cooling rates of approximately $50^{\circ} \mathrm{C} / \mathrm{s}$ required to form martensite in this steel can readily be attained on a run-out table as this cooling step is preformed around the range of the critical heat flux. ${ }^{59)}$ For the Mo-DP steel, employing slow cooling times of $14 \mathrm{~s}$ from 690 to $650^{\circ} \mathrm{C}$ and $20 \mathrm{~s}$ from 720 to $630^{\circ} \mathrm{C}$ lead to ferrite fractions of 0.73 and 0.75 , respectively. Unrealistically long holding times at the ferrite transformation temperatures had to be selected, i.e. cooling from 700 to $635^{\circ} \mathrm{C}$ in $65 \mathrm{~s}$ at a rate of $1{ }^{\circ} \mathrm{C} / \mathrm{s}$ to obtain a ferrite fraction of 0.83 . Even though alloying with $\mathrm{Mo}$ is beneficial in reducing the critical cooling rate for martensite formation it appears that the processing window to establish the desired ferrite-martensite microstructure in the Mo-DP steel is rather limited for run-out table cooling. Ferrite formation times are much longer as compared to those in the L-DP steel and this may be attributable to solute drag by Mo. For run-out cooling such long transformation times are not desirable but for processing DP steels in a hot dip galvanizing line it is beneficial to add alloying elements that delay the transformation to both ferrite and bainite. For example, in the zinc bath metastable austenite is still present and the formation of bainite has to be suppressed.

Table 9 provides a comparison of the predicted and the measured ferrite fractions and ferrite grain sizes. In all

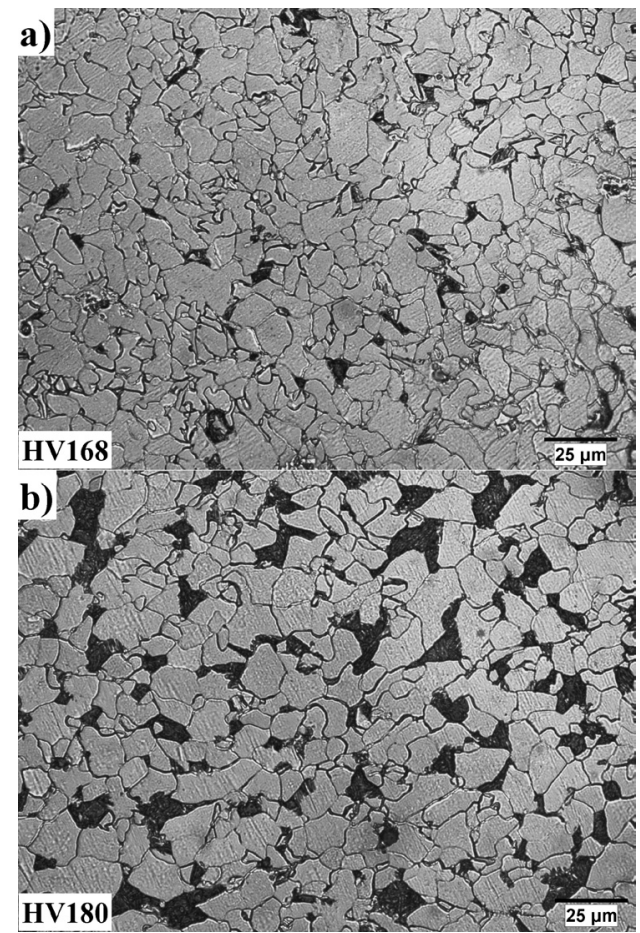

Fig. 9. Dual phase microstructures produced during hot torsion simulations of the industrial rolling schedule followed by run out table stepped cooling simulations in the L-DP steel with slow cooling from 750 to $720^{\circ} \mathrm{C}$ for $7 \mathrm{~s}$ (a) and the Mo-DP steel with slow cooling from 700 to $635^{\circ} \mathrm{C}$ for $65 \mathrm{~s}$ (b), respectively.

cases, the predictions are in excellent agreement with the metallographic observations. This illustrates the predictive capabilities of the proposed model for both the L-DP and the Mo-DP steels.

\section{Conclusions}

A microstructure process model is proposed for hotrolled DP steels with a ferrite-martensite microstructure. The model employs approaches for austenite conditioning that had already been established for conventional steels. The austenite-to-ferrite transformation model is based on concepts previously proposed for plain carbon steels but this model has been shown to have good predictive capabilities for the complex stepped cooling paths required in DP steel production. Further, a model component has been added for the martensite transformation by including a critical cooling condition for complete transformation of remaining austenite into martensite. The model has been validated with laboratory simulations of the entire hot strip mill processing route.

The present results indicate that for the L-DP steel with a plain $\mathrm{CMnSi}$ chemistry robust processing paths can be designed for hot strip rolling, in particular for stepped cooling on the run-out table. However, the present study suggests much narrower processing windows for the Mo-DP steel 
and, given that Mo is added as a costly alloying element, it appears that this grade is not particularly suited for a hotrolled DP steel.

Currently, the proposed model can only describe the formation of ferrite-martensite dual-phase microstructures. Only a very initial attempt has been made to provide also some information on the bainite formation by delineating critical cooling conditions to form bainite instead of martensite. Further investigations are required to develop suitable models to describe the bainite reaction under runout table cooling conditions. Such models are of significance for hot-rolled ferrite-bainite steels or even more complex steels with a ferrite-bainite-martensite structure.

\section{Acknowledgements}

The financial support received from the Natural Sciences and Engineering and Research Council of Canada, Dofasco Inc. and INTEG Process Group, Inc. is acknowledged with gratitude. The materials used for this study had been supplied by Dofasco Inc. and Stelco Inc., respectively. The authors would like to thank B. Nelson and W. J. Poole for stimulating discussions as well as J. Huang and P. Petkov for their help with experimental studies for the Mo-DP steel.

\section{REFERENCES}

1) J. Shaw, B. Engl, C. Espina, E. C. Oren and Y. Kawamoto: New Steel Sheets and Steel Bar Products and Processing, SAE-SP 1685, ed. by D. W. Anderson et al., SAE, Warrendale, PA (2002), 63.

2) M. Militzer: Science, 298 (2002), 975.

3) G. Buzzichelli and E. Anelli: ISIJ Int., 42 (2002), 1354.

4) T. Heller and A. Nuss: Ironmaking Steelmaking, 32 (2005), 303.

5) J. Huang, W. J. Poole and M. Militzer: Metall. Mater. Trans. A, 35A (2004), 3363

6) T. Waterschoot, L. Kestens and B. C. De Cooman: Metall. Mater. Trans. A, 33A (2002), 1091

7) N. D. Beynon, S. Oliver, T. B. Jones and G. Fourlaris: Mater. Sci. Technol., 21A (2005), 771.

8) S. Sun and M. Pugh: Mater. Sci. Eng. A, A335 (2002), 298.

9) T. Waterschoot, A. K. De, S. Vandeputte and B. C. De Cooman: Metall. Mater. Trans. A, 34A (2003), 781 .

10) T. Waterschoot, B. C. De Cooman and D. Vanderschueren: Ironmaking Steelmaking, 28 (2001), 185.

11) W. Gan, S. S. Babu, N. Kapustka and R. H. Wagoner: Metall. Mater. Trans. A, 37A (2006), 3221.

12) S. Oliver, T. B. Jones and G. Fourlars: Mater. Sci. Technol., 23 (2007), 55 .

13) A. Bag, K. K. Ray and E. S. Dwarakadasa: Metall. Mater. Trans. A, 32A (2001), 2207.

14) B. C. Hwang, T. Y. Cao, S. Y. Shin, S. H. Kim, S. H. Lee and S. J. Kim: Mater. Sci. Technol., 21 (2005), 967.

15) K. S. Park, K. T. Park, D. L. Lee and C. S. Lee: ISIJ Int., 45 (2005), 1352.

16) J. Neutjens, P. Harlet, T. Bakolas and P. Cantinieaux: 40th Mech. Working Steel Processing Conf. Proc., Vol. XXXVI, ISS, Warrendale, PA, (1998), 311.

17) A. P. Coldren and G. Tither: J. Met., 30 (1978), No. 4, 6.

18) C. M. Sellars and J. A Whiteman: Met. Sci., 13 (1979), 187.

19) C. M. Sellars: Sheffield Int. Conf. on Working and Forming Processes, ed. by C. M. Sellars and G. J. Davies, Met. Soc., London, UK, (1980), 3

20) M. Suehiro, K. Sato, Y. Tsukano, H. Yada, T. Senuma and Y. Matsumura: Trans. Iron Steel Inst. Jpn., 27 (1987), 439.

21) J. H. Beynon and C. M. Sellars: ISIJ Int., 32 (1992), 359.

22) O. Kwon, K. J. Lee, J. K. Lee, K. B. Kang, J. K. Kim, J. D. Lee and J. Kim: HSLA Steels'95, ed. by G. Liu, H. Stuart, H. Zhang and C. Li, China Science \& Technology Press, Beijing, (1995), 82.
23) J. Andorfer, D. Auzinger, B. Buchmayr, W. Giselbrecht, G. Hribernig, G. Hubmer, A. Luger and A. Samoilov: Thermec'97, ed. by T. Chandra and T. Sakai, TMS, Warrendale, PA, (1997), 2069.

24) I. V. Samarasekera, D. Q. Jin and J. K. Brimacombe: 38th Mechanical Working Steel Processing Conf. Proc., Vol. XXXIV, ISS, Warrendale, PA, (1997), 313.

25) A. J. Trowsdale, K. Randerson, P. F. Morris, Z. Husain and D. N. Crowther: Ironmaking Steelmaking, 28 (2001), 170.

26) Y. Saito: Mater. Sci. Eng. A, $\mathbf{A 2 2 3}$ (1997), 134.

27) A. Perlade, D. Grandemange and T. Iung: Ironmaking Steelmaking, 32 (2005), 299

28) Y. J. Lan, D. Z. Li, X. C. Sha and Y. Y. Li: Steel Res. Int., 75 (2004), 462.

29) P. D. Hodgson and R. K. Gibbs: ISIJ Int., 32 (1992), 1329.

30) B. Buchmayr, A. Samoilov, L. Lachmann and G. Aigmuller: Proc. 1st Int. Conf. on Modelling of Metal Rolling Process, The Institute of Materials, London, UK, (1993), 134.

31) M. Pietrzyk: Mater. Proc. Techn., 125-126 (2002), 53.

32) M. Militzer, E. B. Hawbolt and T. R. Meadowcroft: Metall. Mater. Trans. A, 31A (2000), 1247.

$33)$ D. Liu, M. Militzer and W. J. Poole: Mater. Sci. Forum, 539-543 (2007), 4391.

34) A. Samoilov, Y. Titovets, N. Zolotorevskii, G. Hribernig and P. Stiaszny: Proc. 2nd Int. Conf. Processing Materials for Properties, ed. by B. Mishra and C. Yamauchi, TMS, Warrendale, PA, (2000), 639.

35) F. Fazeli and M. Militzer: Steel Res., 73 (2002), 242.

36) F. Fazeli and M. Militzer: Solid-Solid Phase Transformations in Inorganic Materials 2005, ed. by J. M. Howe, E. D. Laughlin, J. K. Lee, D. J. Srolovitz and U. Dahmen, TMS, Warrendale, PA, (2005), 835.

37) H. N. Han and S.-H. Park: Mater. Sci. Technol., 17 (2001), 721.

38) D. Liu, F. Fazeli, M. Militzer and W. J. Poole: Metall. Mater. Trans. A, 38 (2007), 894

39) ASTM Standard Designation: E112-88, 1994 Annual Book of ASTM Standard, Vol. 3.01, ASTM, Philadelphia, PA, (1994), 227.

40) A. Giumelli, M. Militzer and E. B. Hawbolt: ISIJ Int., 39 (1999), 271.

41) U. F. Kocks and H. Mecking: Prog. Mater. Sci., 48 (2003), 171.

42) H. J. Frost and M. F. Ashby: Deformation Mechanism Maps, Pergamon Press, Oxford, (1982), 20.

43) M. Onink, C. M. Brakman, F. D. Tichelaar, E. J. Mittemeijer and S. van der Zwaag: Scr. Metall., 29 (1993), 1011.

44) M. Avrami: J. Chem. Phys., 8 (1940), 212.

45) W. P. Sun, M. Militzer, E. B. Hawbolt and T. R. Meadowcroft: Trans. ISS, 25 (1998), No. 5, 85.

46) M. Dubois, A. Moreau, M. Militzer and J. F. Bussière: Scr. Mater, 39 (1998), 735

47) A. Smith, S. E. Kruger, J. Sietsma and S. van der Zwaag: ISIJ Int., 46 (2006), 1223.

48) M. Militzer, R. Pandi and E. B. Hawbolt: Metall. Mater. Trans. A, 27A (1996), 1547.

49) M. Militzer: ISIJ Int., 47 (2007), 1.

50) J. Ågren: Scr. Metall., 20 (1986), 1507.

51) S. Lacroix, Y. Brechet, M. Veron, D. Quidort, M. Kandel and T. Iung: Austenite Formation and Decomposition, ed. by E. B. Damm and M. J. Merwin, TMS, Warrendale, PA, (2003), 367.

52) J. R. Bradley and H. I. Aaronson: Metall. Mater. Trans. A, 12A (1981), 1729.

53) F. Fazeli and M. Militzer: Metall. Mater. Trans. A, 36A (2005), 1395.

$54)$ G. P. Krielaart, J. Sietsma and S. van der Zwaag: Mater. Sci. Eng. A, A237 (1997), 216

55) M. Lusk and H. J. Jou: Metall. Mater. Trans. A, 28A (1997), 287.

56) I. Tamura, H. Sekine, T. Tanaka and C. Ouchi: Thermomechanical Processing of High Strength Low Alloy Steels, Butterworth and Co., London, UK, (1988), 21.

57) M. Suehiro, K. Sato, Y. Tsukano, H. Yada, T. Senuma and Y. Matsumura: Trans. Iron Steel Inst. Jpn., 27 (1987), 439.

58) D. Hall and J. Worobec: Phase Transformations during the Thermal/Mechanical Processing of Steel, ed. by E. B. Hawbolt and S. Yue, Metall. Soc. of CIM, Montreal, PQ, (1995), 305.

59) V. Prodanovic and M. Militzer: Pipelines for the 21st Century, ed. by W. Chen, The Metallurgical Society of CIM, Montreal, PQ, (2005), 127. 